\title{
Analysis of an English Textbook from a Feminist Perspective
}

\author{
Jagadish Paudel*, Prabin Khadka \\ Department of Education, Tribhuvan University
}

*Corresponding Author: Jagadish Paudel, Department of Education, Tribhuvan University

\begin{abstract}
Textbooks provide guidelines for both teachers and students and play a vital role in shaping students' behaviors and ideology. Hence, textbooks should be analyzed to explore the potential impact they make upon students. This study was executed to explore the representation of males and females in terms of status, roles, occupations and activities in Grade Nine English textbook of Nepal. In order to explore these aspects, this study employed a descriptive approach. The data were collected through self-observation and focused reading. Based on seven different criteria, the data were gathered viz. order of presentation, role assigned to males and females, occupations and activities assigned to males and females, use of sexist language, images and visibility, clothes they wear, and the number of male and female pictures. The collected data were analyzed based on four key principles suggested by Lazar (2007). Findings revealed that males are given higher occupational roles while females are given conventional, nurturing and lower prestigious roles. Further, it was found that women are portrayed in the relegated position; and they are presented as weak, secondary, and inferior to the males. Therefore, this study evokes that the textbook writers should harmonize gender equality while writing textbooks so that female students do not feel inferior to males and vice-versa.
\end{abstract}

Keywords: textbook analysis, feminist analysis, female representation in textbook

\section{INTRODUCTION}

Coursebook and textbook are used synonymously. Coursebook often comprises of content, activities, exercises and tasks and is regularly used for the classroom purpose in schools and colleges. It is designed to fulfill course's objectives. A good course book is beneficial for both teachers and students since it provides a clear guideline to them for teaching learning activities. Concerning the English language text-book, it provides a good exposure for learners since it can be used as a source for presentation of language materials; as a source of activities for learners' practice and communicative interaction; as a reference material for grammar, vocabulary etc.; as a source of stimulation and ideas for classroom language activities; as a syllabus; as a resource for self-directed learning and self-access work; as a good resource for less experienced teacher (Cunningsworth, 1995).

Textbooks are most widely used teaching materials in the classroom. They aim at providing learners with necessary knowledge, language skills and information regarding various areas. Regarding English textbook, Sheldon (1987) defines textbook as "a published material specially designed to help language learners to improve their linguistic and communicative abilities" (p.23). The ultimate goal of textbook is to help language learners to achieve 'linguistic and communicative abilities'. Concerning textbook, Ur (2009) writes "textbook as a framework which leads learners and teachers in a specific direction" (p.128). She further states that textbooks are road map through which teachers and learners know what they are learning, and what they want to accomplish from the course. Textbook is systematic presentation of pre- packaged set of teaching learning materials which are prepared considering learners' level, interest and needs, and it offers a framework for guidance and orientation to them (Hutchinson and Torres, 1993).

In Nepali context, textbooks are taken as most important teaching learning materials. However, they are not evaluated and analyzed to explore whether they suit students' level or not, whether they maintain cultural, social norms and values or not, and to find out how gender relations are portrayed in the content, visual images and exercises. It is desirable that textbooks should be free from any kind of biasness and prejudice such as cultural, social, political and gender discrimination. As concerns to gender discrimination, Cameron (1992) writes "Gender-biased language in textbooks can affect students adversely and it creates an oppressive world for them because this gender-biased language 
most often is unjustified and unfair" (p. 13). Gender bias of textbooks does not inculcate female students into the habit of reading the text, rather they feel a sense of biased and humiliation.

This study is based on the English textbook of grade nine of Nepal. The textbook has been prepared by the three authors: Bishow Raj Joshi, Lalmani Joshi and ParbatiDhungana. Among three authors, two of them are males, and only one is female. Similarly, we go through other textbooks prepared in Nepal, we find the same scenario i.e. the male dominance. By this, it can be interpreted as only few numbers of females are in the position and condition of writing textbooks, and the large numbers of males have access to writing textbooks. When we go through the grade nine textbook, we can find male dominance inside the text, too. In the textbook, only one poem was included written by both male and female. No single text has been presented written by a female writer in the textbook. It shows that literary works composed by the males are primary to the literary works composed by females. The content of the textbooks helps to reinforce gender as a social division and perpetuate inequalities between men and women. Therefore, the content of the textbooks, the issues, sentence models and examples must be represented in such a way that both male and female learners feel that they are equally valuable for society. Textbooks should not impose on the readers the idea that male students have more social prominence than females. However, if we glance at the current EFL textbooks of Nepal, it is found that there is gender-bias in the design of the textbooks. There seems little balance and equality between male and female characters in the content of the textbooks.

Bhusal (2019), in "The rhetoric of racism and anti-miscegenation Laws in the United States," emphasizes that "What is necessary at this point is, with the tools offered in critical race theory, is to complete a deeper study of minorities and bring their stories, their voices, into academic scholarship" (p. 88), and at the same time bring feminist voices into the forefront. Both feminism and critical race theory share similar principles in terms of uplifting the conditions of the marginalized and bringing inequality into floor. However, for this article, I will be analyzing an English text from a feminist perspective. The grade nine textbook can be analyzed based on Lazar's (2007, pp.144-150) four key principles of feminist critical discourse analysis. The principles have been described briefly below.

\subsection{Feminist Analytical Activism}

Feminist analytical activism focuses on the establishment of the social order through a "critique of discourse'. Lazar (2007) states that "The central concern of feminist critical discourse analysts is with critiquing discourses which sustain a patriarchal social order - relations of power that systematically privilege men as a social group, and disadvantage, exclude, and disempower women as a social group" (p. 145). The feminist critical analyst aims to bring transformation and raise the critical awareness to expose the domination and discrimination to females found in the discourses, and it also reveals what is done to sustain a patriarchal social order. It analyzes the inequality prevalent in the society and makes aware people logically to the gender discrimination. The job of feminist analytical activists is to raise awareness among people about gender inequality through researches and teaching. The work undertaken by the feminist is described as the academic activism (Lazar, 2007).

\subsection{Gender as an Ideological Structure}

It is commonly accepted that gender is socially constructed. Society has divided men and woman in terms of works and in pursuing other cultural rituals. Men are in a superior position and enjoy more power than women. Women are often relegated to a lower positon; and accordingly, they are assigned works and power (Tyson, 2006). In this context, it is worth mentioning Bhusal's (2007) work where he says, "We, as students of rhetoric, need to continue to look for other women rhetors who have been largely marginalized or ignored and reclaim their contributions in the twenty-first century" (p. 56). His point is that "The effects of years of marginalization or suppression are being rectified as interest and scholarly studies are illuminating their impressive literary and rhetorical gifts. Many of the reforms in societal attitudes toward women that they championed are being realized" (p. 56). It means the twenty-first century will be an important period in history for females in terms of their rhetorical presence.

From a feminist perspective, Lazar (2007) argues that "the prevailing conception of gender is understood as an ideological structure that divides people into two classes: men and women based on a hierarchal relation of domination and subordination respectively" (p.146). There is discrimination in terms of hierarchy and domination between males and females. For instance, use of male nouns and 
pronouns for generic purpose gives male members symbolic capital where males are visible and females are invisible (Spender, 1985). Gender ideology and domination creates a 'hegemonic' situation which puts males to be in the higher position of social hierarchy. In this regard, Lohani (2019), in "Constructing nontraditional rhetoric: Critical study on GloriaAnzaldua and Suresh Canagarajah," states that "whether it is the males dominating the females or the believers of heterosexual normativity looking down upon the peoples of different gender orientations, there is a constant tension between the practitioners of homogeneity and diversity"( p.118). In this tension, however, it is the males that enjoy an upper hand over females and this reflects, like in other fields, in the curricula that are largely devised by the males.

\subsection{Complexity of Gender and Power Relationship}

Feminist CDA is to examine how power and dominance are discursively produced and resisted in a variety of ways through textual representation of gender. The relationship between gender and power is very complex and subtle. Feminist CDA aims to uncover the complex relationship between gender and power. Lazar says, "Power relations are a struggle over interest which are exercised, reflected, maintained and resisted through a variety of ways, modalities, extends and degree of explicitness (Lazar, 2007). She further writes:

Overt forms of gender asymmetry or sexism, traditionally, have included exclusionary gatekeeping social practices, physical violence against women, and sexual harassment and denigration of women. Such overt manifestations of power (or the threat of it) remain a reality for women in many societies, even where there is legislation against blatant gender discrimination. (148)

The power had/has distributed unequally between men and women whether in past or present. Consequently, in society, males became more powerful and they oppressed and exploited women physically, sexually, and they are belittled. Though, ascertaining equal right and power has been a global slogan now; however, we can still see an open gender discrimination legislation in some countries.

\subsection{Discourse in the (de) Construction of Gender}

Feminist CDA assumes that discourse is one among several elements of social practices. Lazar (2007) argues " the interest of feminist CDA lies in how gender ideology and gendered relations of power get (re) produced, negotiated, and contested in the representation of social practices in social relationship between people" (p. 149). From her argument it is clear that the central concern of feminist CDA is to analyze how power shapes gender ideology and gender structure and focuses on how males and females are presented in the text. Gender is constructed in two ways: co-construction of gender (men and women) and construction of masculinity (Lazar, 2007). The data in feminist CDA include different forms of semiotics such as visual image, layout, gestures and actions in text and talks. Furthermore, they also critically analyze the choices of lexis, clauses/ sentences/ utterances, conversation turns, structure of argument and interaction among discourses (Lazar, 2007).

\subsection{Context}

Textbooks not only provide factual information about subject matter, but they also help shape behavior and ideology of children and through which they are guided. It has a great impact on shaping children's behavior. Hence, textbook writers should write textbooks harmonizing gender equality; otherwise they may shape superiority to one while inferior to other. The visibility, status and perceive potential of boys and girls, men and women should be portrayed in textbooks in a welladjusted way. However, if we go through the school level textbooks of Nepal, there can be found gender discrimination. The textbooks have not been analyzed critically from a feminist perspective. Critical textbook analysis is one of the most few researched areas in our context; so, we felt a dire need of research of carrying out a study in the area. In Nepal, the English textbook for grade nine has not been critically examined from feminism perspective. Therefore, this study was carried out to show females portrayal in the textbook.

\section{MeTHOdOLOGY}

This study adopted a descriptive approach to study grade nine English textbook of Nepal. The textbook was analyzed based on four CDA framework: feminist analytical activism, gender as an 
ideological structure, complexity of gender and power relationship and discourse in the (de) construction of gender (Lazar, 2007). Lazar states "feminist criticism as a political perspective on gender, concerned with demystifying the interrelationships of gender, power and ideology in discourse" (p.144). Feminist critical approach offers a wide range of tools and strategies for detailed analysis of contextualized uses of language on texts and raises the voice against patriarchal society and male stereotype culture and raises awareness. She further states that feminism is a problem oriented discipline as it focuses on gender problem. It also suggests the usefulness of language and discourse studies for the investigation of feminist issues in gender and women's study. While analyzing a text from feminist perspective language is critically analyzed together with other semiotic modalities like visual image, gesture and so on and also critically analyzes the gender biased language i.e. sexist language used in the text. It tries to seek how females are treated and how they should be treated. So feminism is concerned with the marginalization of all women. Feminist CDA embrace multimodal frameworks (Kress \& van Leeuwen, 1996; Scollon, 2001). It is commonly found that the language in CDA research is increasingly critically analyzed together with other semiotic modalities like visual images, layouts, gestures, and sounds, which makes for an enriching and insightful analysis (Lazar, 2007).

This study was based on the secondary data which was obtained from the contents of the textbook. The data were described both quantitatively and qualitatively. The data were collected through selfobservation and focused reading. The pictures and images were critically observed and also counted them. To analyze the textbook, the content and language used in the textbook was read and re-read. In the first part, the data were analyzed using quantitative data analysis procedure and presented in figures -statistically, and in the second part, the data were critically analyzed, described and interpreted

\section{RESULTS AND DISCUSSION}

Based on the data obtained from the textbook, findings and discussion have been drawn.

\subsection{Order of Presentation and Character (First-Ness)}

By a close observation of the text, it is found that in most of the cases males are presented prior to the females in the textbook. There are a few instances of female being referred to first in a sentence and conversations, although the pattern could be reserved. In most of the cases male characters and male pronouns is presented prior to the female characters and female pronouns. For example pronoun 'he' is followed by 'she', 'him' by 'her', 'Mr' is followed by 'Mrs' / 'Miss' and so on. In the textbook, there are altogether sixteen conversations where eleven conversations are initiated by the male characters and only five is by female characters. It shows the 'stereotypical gender' roles where the females are mentioned in reference to the male characters. And also, it shows females are not supposed to speak first, rather they are supposed to speak only after listening males. Furthermore, male dominance is found in the speech, and which can be interpreted as females should speak less and listen more. The conversation initiated by males and females can be clearly understood by the following bar chart.

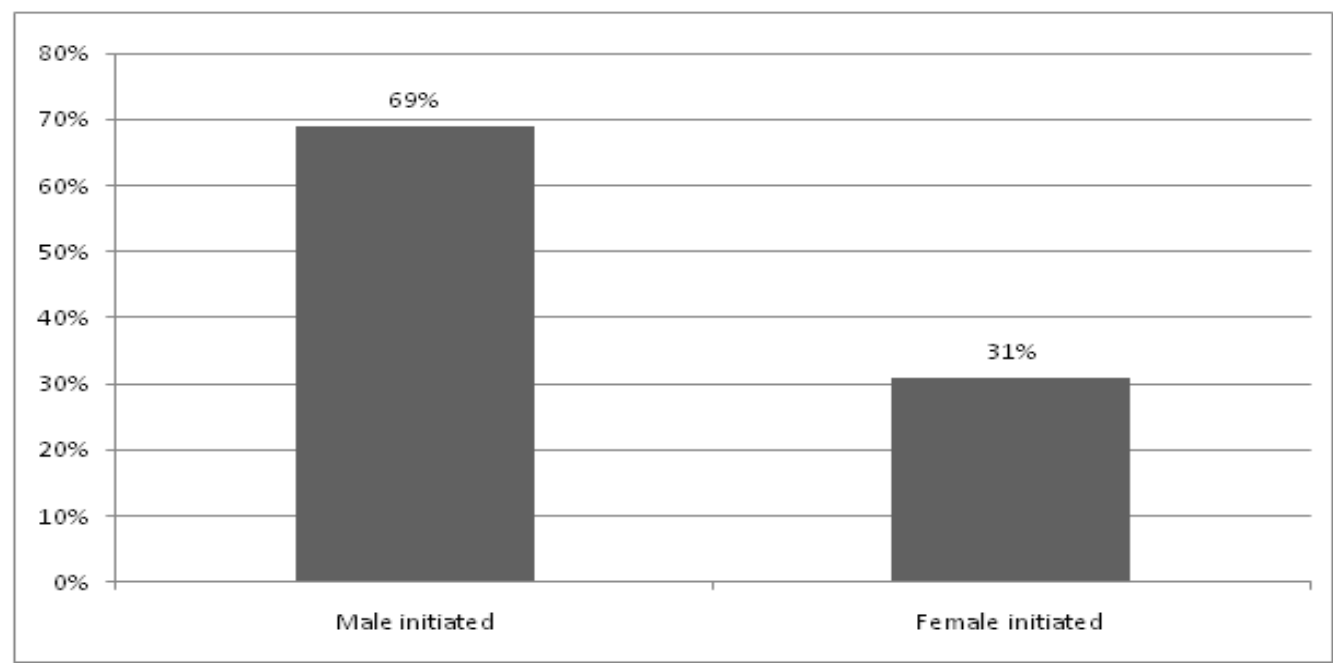

Figure1 


\subsection{Participation of Males and Females in the Conversation}

From the analysis of the conversation given in the text, it is found that there is an extreme dominance over females in terms of the participation in the conversation. Conversations having only female characters are few in number; hence, it can be clearly implied that females in the textbook of the grade nine are dominated in terms of participation in the conversation. The number of conversation having only male characters is high in comparison to the number of conversation having only female characters. Forty four percent of conversation includes both male and females and 18 percent conversation have neutral pronoun like 'you', 'a', 'b' and so on. The ratio of participation of males and females in the conversation has been shown in the following bar graph.

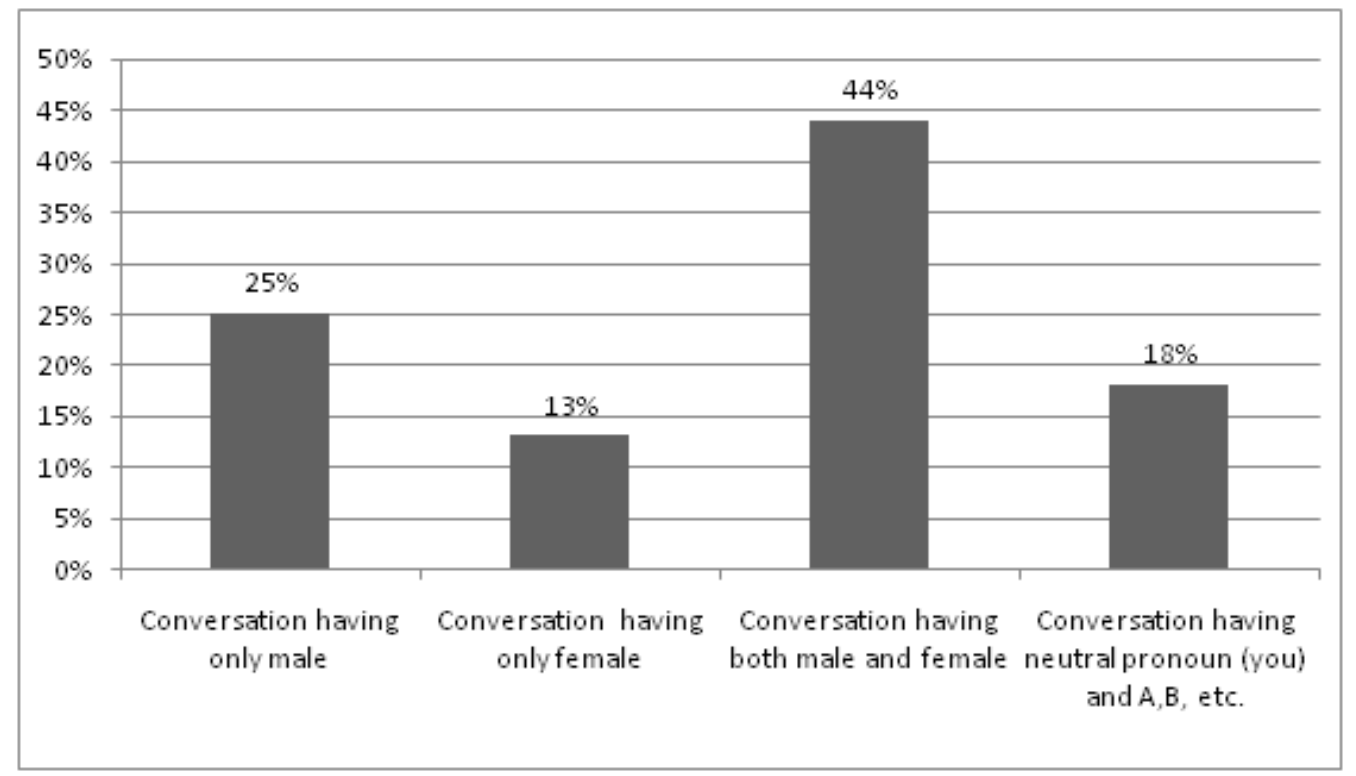

Figure2

\subsection{Images and Visibility of Male and Female Characters}

In terms of images and visibility of the characters, it is also found great dominance of males in the English textbook. There is no equal representation of female characters in the text and images. There are altogether 61 pictures, among them in most of the pictures i.e. in 25 pictures only males are presented, and in only 12 pictures females are portrayed and in the remaining 24 pictures, both males and females have been represented. By this, it can be understood that males have been more prioritized in the portrayal than females. And this can lead that humiliation and inferiority to female students and demotivate them to read the text.

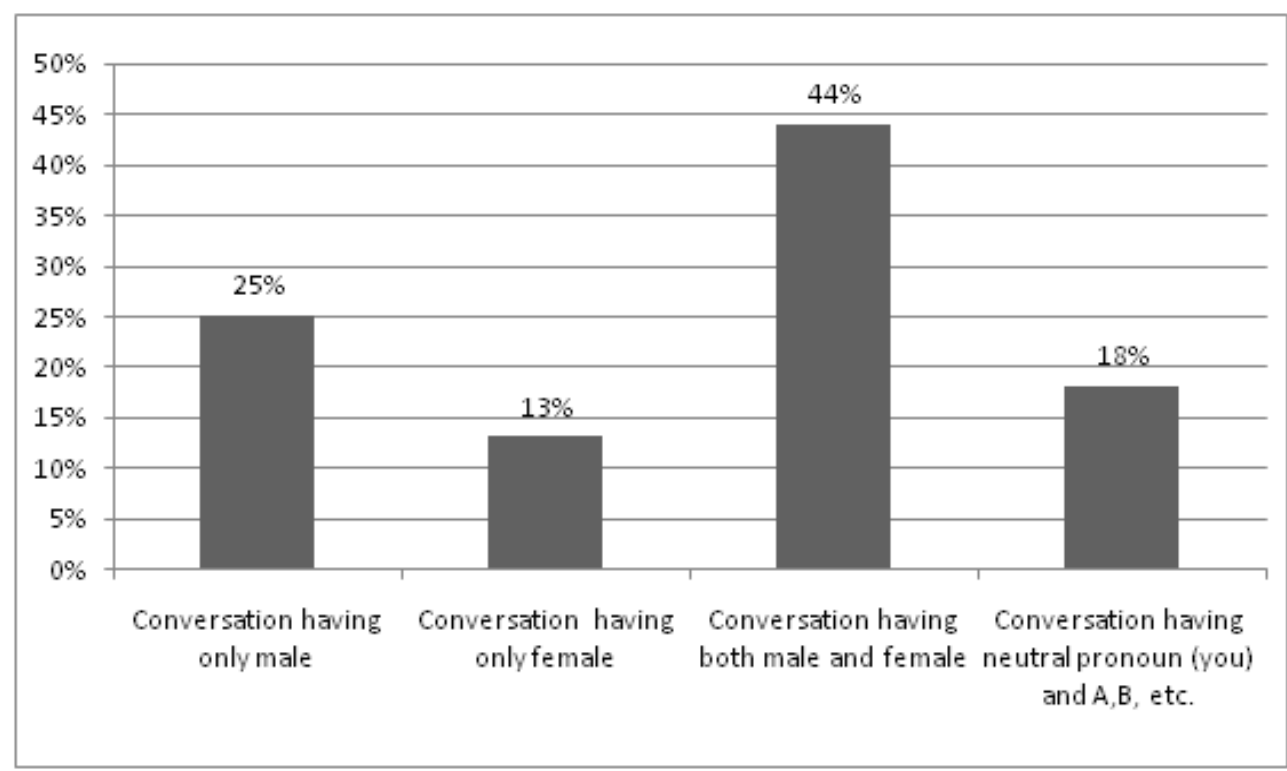

Figure3: Number of Male and Female Pictures 


\subsection{Roles, Activities, Occupations and Position Assigned to the Males and Females}

The data shows that males are presented as rational, strong, powerful, proactive and independent and females as powerless, dependent, weak emotional and nurturing. In the textbook, males are presented in doing wide range of activities. Males enjoy the occupational roles which are higher in status like doctor, engineer, reporter, photographer and so on. On the other hand, females' occupational roles are conventional, nurturing and caring jobs like teacher, salesgirl, mother and caretaker. For example, on page no. 27 there is an interview with a renowned doctor by a reporter. Role of both doctor and reporter is portrayed by male characters. Similarly, on page no. 29 there is an example of CV of an engineer where male is portrayed as an engineer, and in the CV male name has been given as a referee. Similarly, a notice has been given on page no. 178 where the position of secretary is occupied by male name. By these all data, it can be inferred that males are considered superior in terms of works, activities, occupations and position, which clearly show male dominance tendency in the authors.

Likewise, there is a one act play entitled 'A disaster' on page no. 45. It is about the earthquake where female characters are presented as powerless, helpless, coward and panic but male characters are presented as brave, emotionally strong, courageous and patient. Most of the emotional and panic dialogues are spoken by the female characters like oh! My god what is going to happen? Oh god! Have mercy up on us. Is this the end of our life? What shall we do? Oh! Dear what a pity? This ambulance takes my breath. But males are portrayed as calming and making other characters comfortable. So, it shows that females are coward and emotionally weak but males are strong and can handle the difficult situation being patient and calm.

Similarly, in the book, a debate competition among four students has been given. The four students were Ajmera, Uttar, Chandra and Bhim and they put their own views 'On Going Development and Progress'. Two male characters (Uttar and Bhim) argue people should keep up to be up-to date with this modern world and they should not be limited to what they already have. On the other hand, two female characters (Ajmera and Chandra) are portrayed as satisfying themselves on what they have. They argue on not to be more ambitious and express that they should always have self-satisfaction and cherish what they have. This debate shows females as conventional, traditional and stagnant, but males as modern and progressive. Similarly, in the text, while portraying a successful person, a male character has been presented- Abraham Lincoln. Instead of AbrahmLinclon, the authors could exemplify any woman who are successful in their life. By this, it can be guessed that there are males who are successful in the world.

In page no. 156 reviews of two books have been presented viz. Jhola and Lord of the flies. Both of the books were written by male authors. Among two, at least one could be included written by female author as there are myriad of popular stories, drama, novel and poems composed by female writers. Male author's books are included as if there is no any popular book written by female writers. It shows that women are secondary in literature too. Literary works written by female writers are excluded from the literary canon. It can be interpreted as women's works are not given importance as much as male's works, and they have been shadowed in the literature. The story 'Jhola' by Krishna Dharawasi is about the sati tradition that was prevalent until 1920s. The story is all about the violence against women. It shows that women are the victim and males are superior to females from many years back. It might develop the inferiority feeling among the female students and superior feeling among male students. Instead of including the story of such suffering, story of women's success and glory of women could be included for example, Jiwan Kanda Ki Ful by JhamakKumariGhimire. It describes the successful story of a differently able woman.

Likewise, a sample message of congratulations has been presented on page no. 165 for receiving annual best athletics award for a boy. As an example it could be used a female name and picture. It shows that males dominance on sports too. Similarly, there is an announcement of results of international handwriting competition where three students had taken part and among them two are males and one is female student. And male character has been presented as a winner. It also shows females are secondary to males.

\subsection{Clothes they Wear}

In the text, it is found that men are portrayed wearing a wide range of cloths from casual to formal, even hip-hop dresses. But women are found to be in traditional dresses and in school uniform in most 
of the pictures. This is because most of the pictures portrayed men in engaging varieties of activities while women are presented in engaging some limited activities. In the textbook, women are presented passively like doing household work, and attending school.

\subsection{Use of (Sexist) Language}

Sexist language refers to the use of male dominance language. Male domination language can be found in different books and writings, for example, policeman, chairman, spoke-man etc. The language used in the English textbook is found to be neutral or gender free. There is no use of any sexist language in the text, which is one of the positive aspects of the book.

\subsection{Critical Image Analysis}

Multimodality has been used in the textbook. Bhusal (2019), a multimodal scholar states, "Multimodality refers to multiple modes of communication -- textual, aural, visual, and spatial" (p. 167). With the arrival of new technologies, it is important that we include multimodal composition in textbooks, but we need to know how to incorporate multiple modes into the text. In addition, Bhusal argues, "teacher training should focus on providing guidelines to instructors on how to use technology and on the skills necessary to implement multimodal assignments" (p. 171).Lohani (2019), another scholar investigated in multimodal composition, in "The history of multimodal Composition, its implementation, and challenges states that "with the proliferation of the digital media and other forms of technical innovations taking place at an unprecedented pace, it can be assumed that the multimodality will only occupy greater weight in the curricula and require more attention" (p.128). Lohani's take on multimodality seems to be well incorporated into this textbook.From critical analysis of the images found in the textbook, it has been found that multimodal composition is used as a vehicle or means to show females inferior to males.

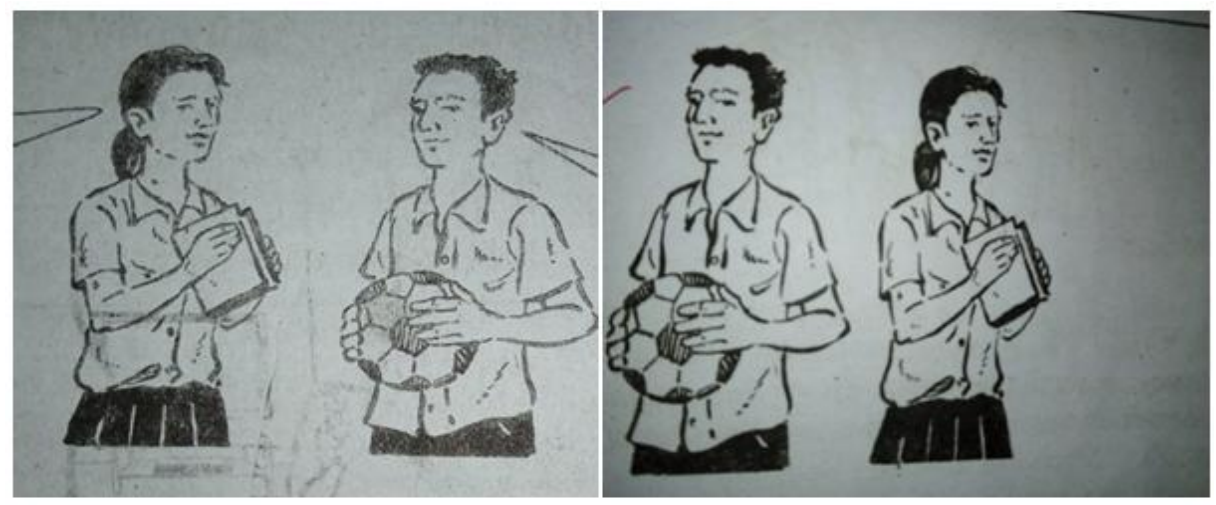

Figure No. 5

The above pictures are taken from page no. 9 and 167 from the textbook. In the side pictures, a girl is holding a book and a boy is carrying a football; and both are seem to be in school uniform. It can be interpreted that females are not interested in and capable of playing games, rather they are bookish; they do not involve in extra-curricular activities, except reading. But the males are portrayed as capable of playing games, that is, they are equally interested in extra- curricular activities. The pictures present females in a narrow way. By this, it can be implied that males do not limit themselves to reading, but females do.
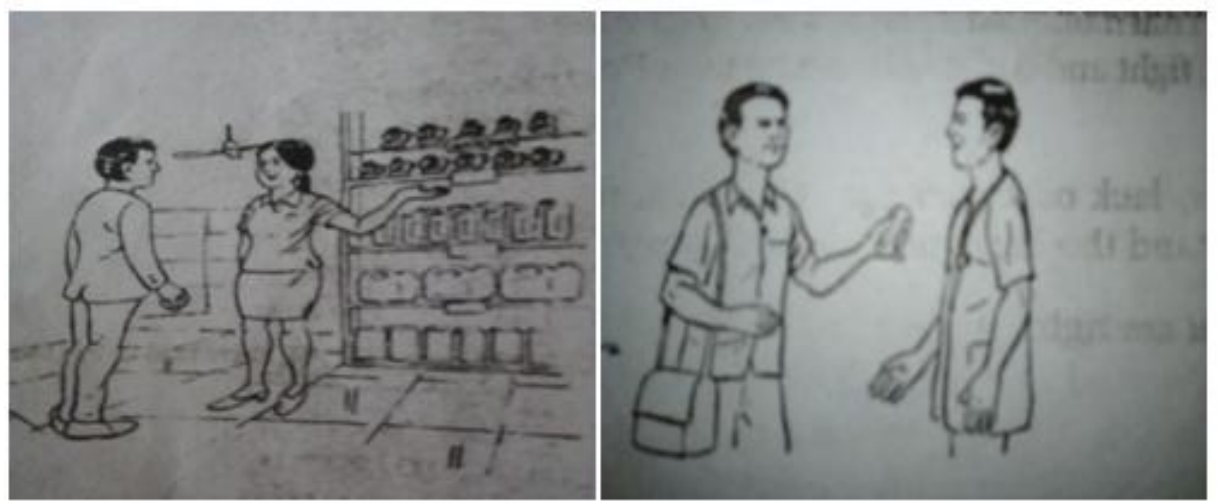


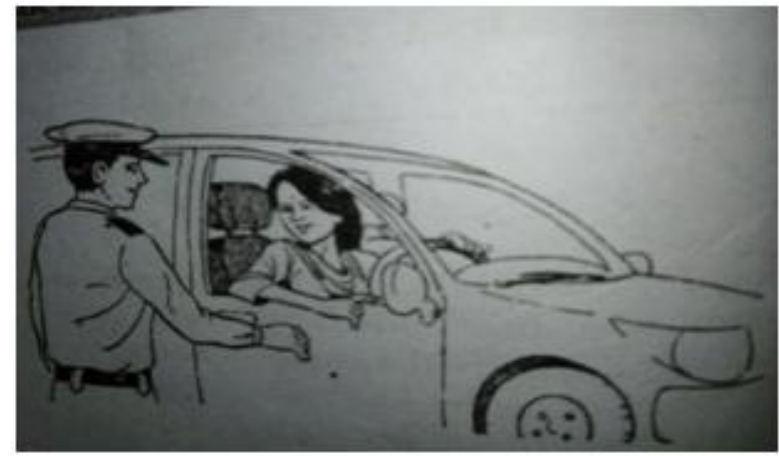

Figure No. 6

The above pictures are taken from page no. 22, 27 and 108 of the book. It can be seen that both males and females are assigned different roles. In the first picture, a young man is going to buy footwear and a young lady is presented as a sale girl. Likewise, in the second picture, the role of both reporter and doctor is portrayed by males, and in the third picture, the role of police is given to a male and the role of driver is given to female though the roles assigned to them could be easily reversed. It presents female engaging in low prestigious job like driver, salesgirl and so on and the males engaging in prestigious job like reporter, police and doctor. Analyzing the above pictures, it can be said that the textbook presents females as in-capable of doing prestigious jobs.

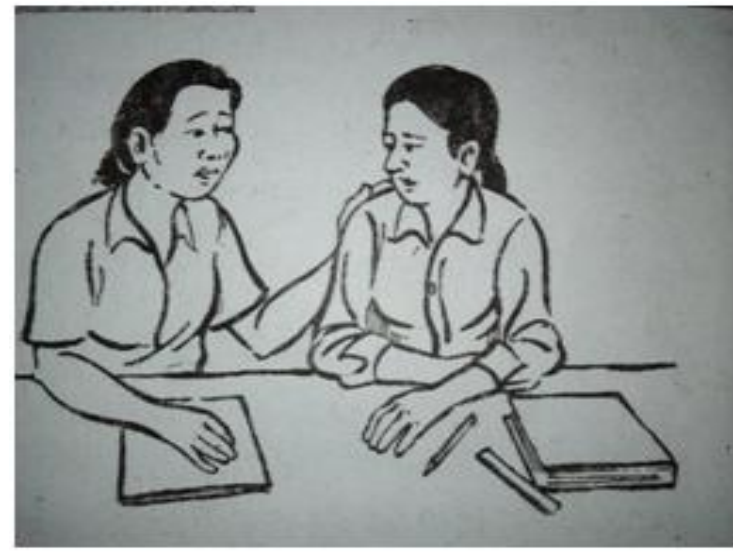

Figure No. 7

The above picture speaks that the ladies in the picture are worried or sad. If we look at the picture with critical eyes, portraying females in a sad state shows that females tend to be emotionally weak in comparison to males. This portrayal of females also links to the way the Nepalese culture governs the overall mentality of the people in that location. Suresh Lohani and others (2015) who also nurses deep interest in cultural rhetorics, in "Scholar's Social Studies and Creative Arts" says that " culture is the way of life. People living in a society practice a lifestyle which is directly or indirectly influenced by their culture" (p.39). Thus, the sad expressions worn by girls in the picture exemplifies the societal way of life that has been perpetuating in the Nepalese society from hundreds of generations.
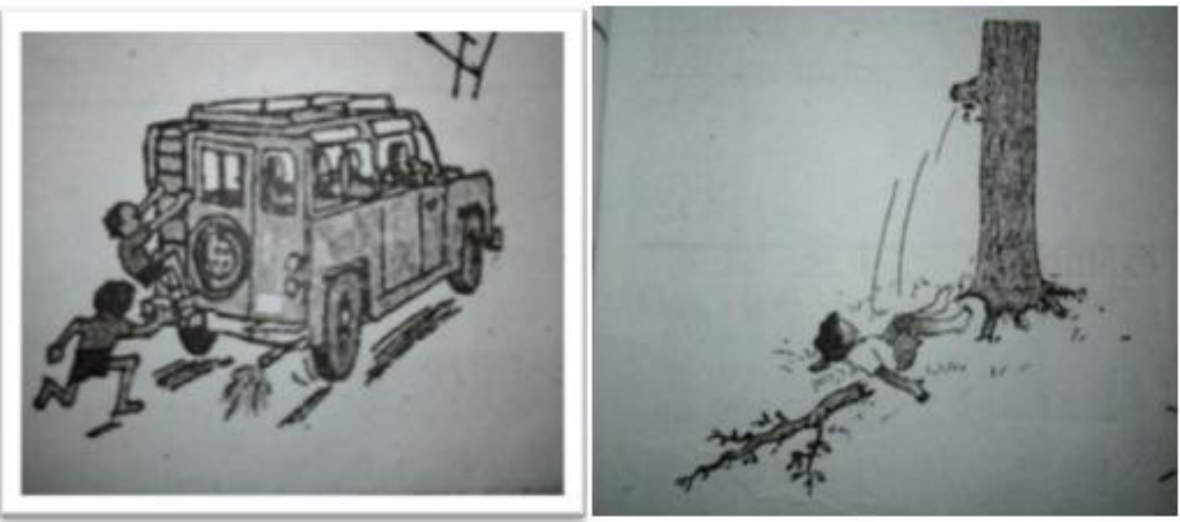


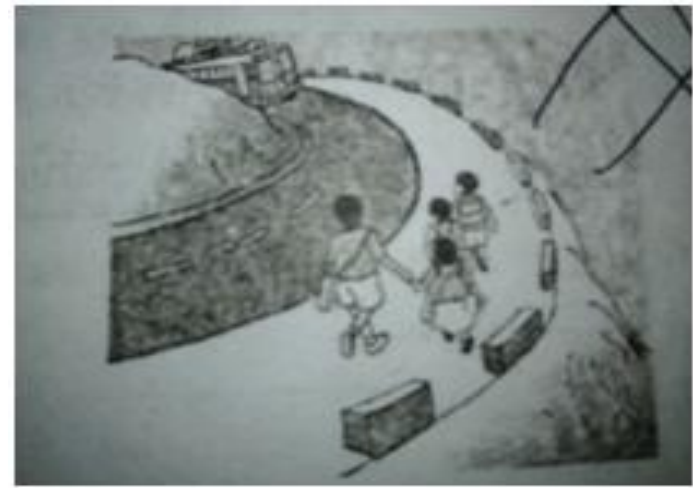

Figure No. 8

In the first picture, two boys are running after the taxi, and in the second picture, a boy fell off from the tree. The use of males' pictures to show such activities shows that boys can take risks whether they get success or not. The above pictures present males as courageous and risk-takers. Similarly, in third picture, it has been shown that some people are going to school or returning from the school. In the picture, a little girl is holding her hand with an elder man, and a boy seems to be the same age walks independently on the road ahead of all. It presents females always depend on males from their early life.

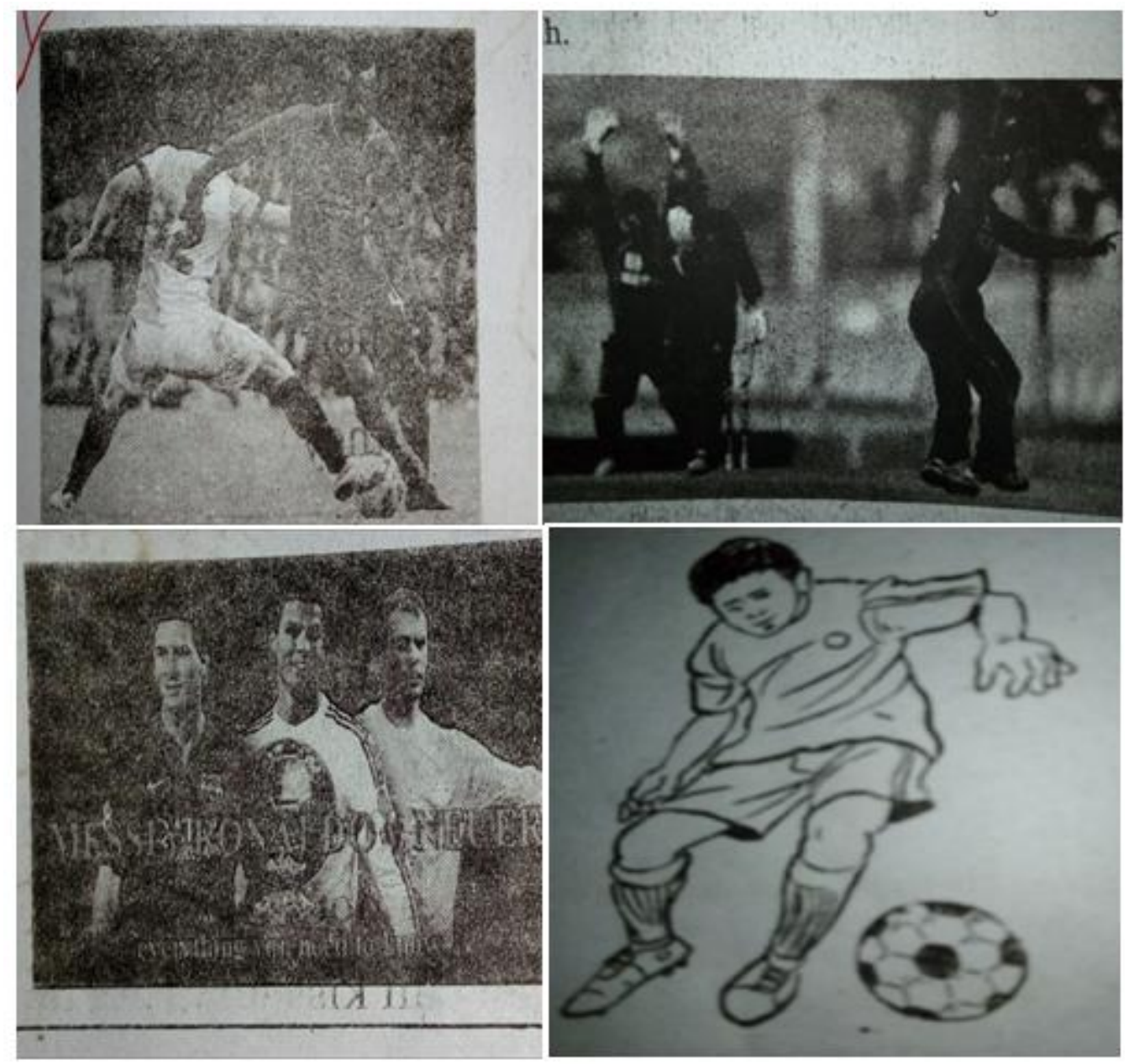

Figure No. 9

The above pictures are all about sports, where players are playing football and cricket and three famous football stars are also presented. Simply, there is nothing wrong with it, but if we observe critically, we can smell the gender bias. In all pictures, there is use of only male players as if females do not play games and there are no any female players as famous as male players. Though, there are number of female players as famous as male players, the above pictures show that there are only male famous players. 


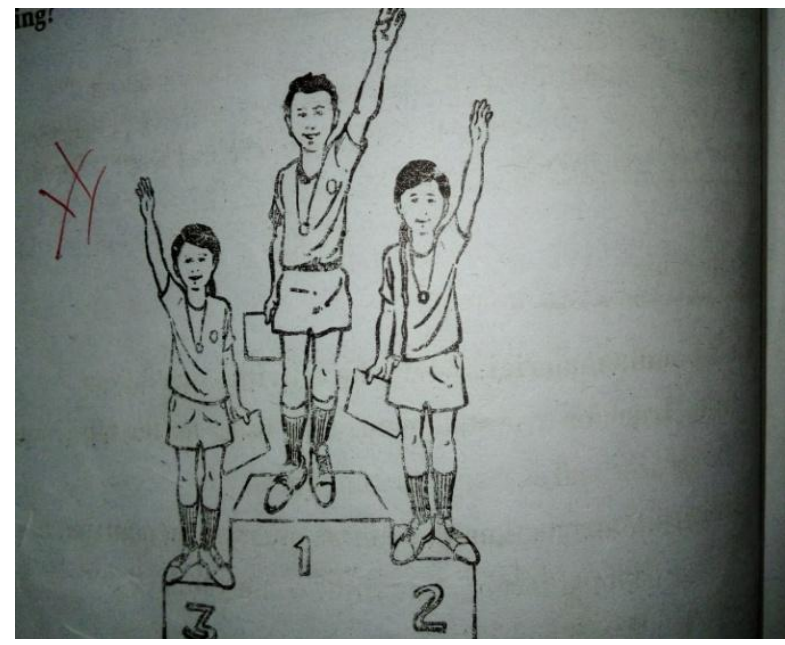

Figure No. 10

The above picture shows the winner, first runner-up and second runner-up of some event. Here, also we can see the male dominance. A male is presented holding first position and females as second and third position even though there are two female participants. It shows females are always secondary to males, and males are always more forward than females in every sector.

Moreover, in the textbook, boys are presented doing various activities like playing football, cricket, running, climbing tree, being winner and so on. But females are mostly presented reading, writing, taking care of others, sitting and gossiping etc. It shows female are passive or less active in comparison to males, they are inferior and capable of doing only some limited easy tasks. For example
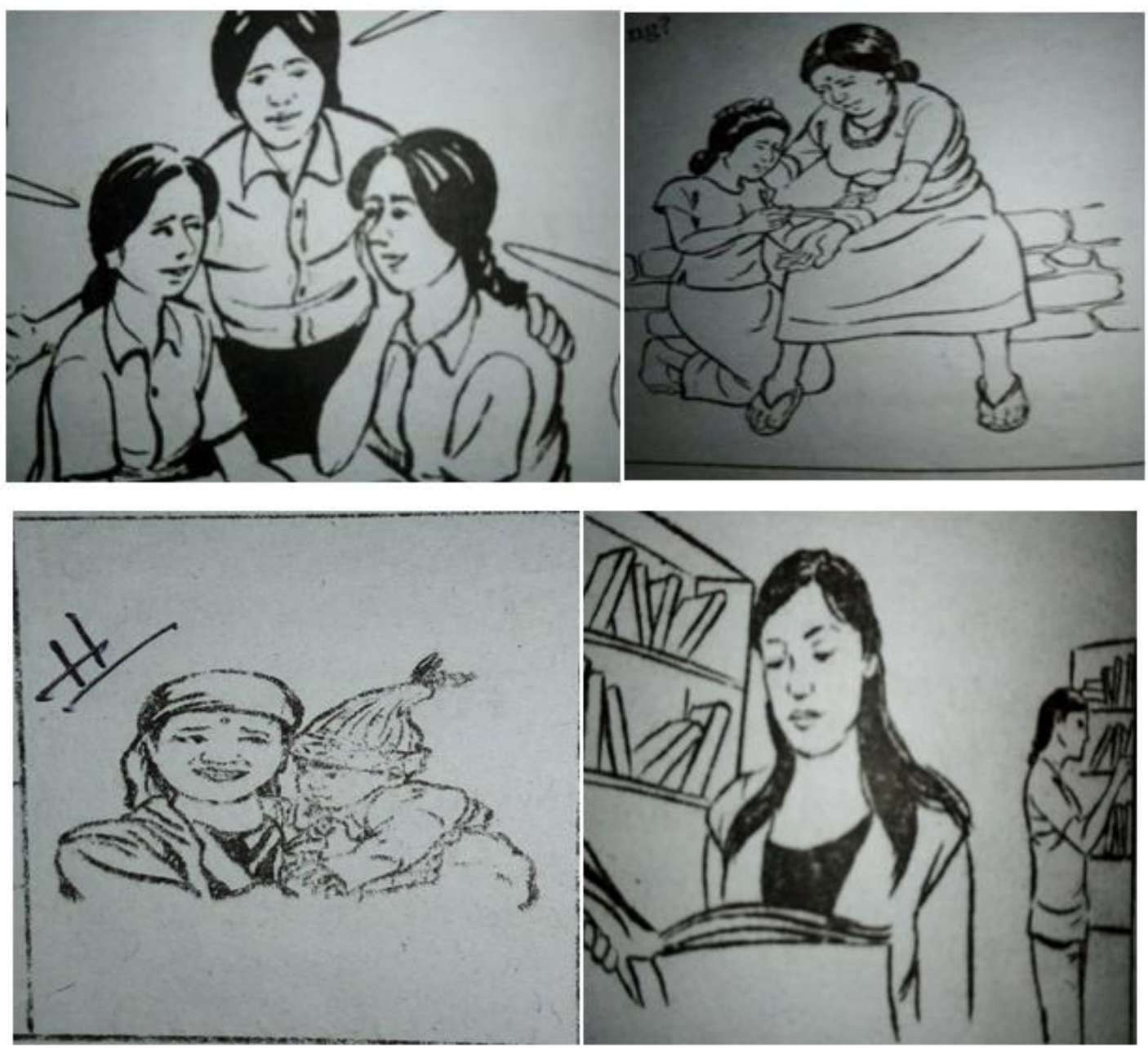

Figure No.11 


\section{CONCLUSION}

This study was carried out with the aim of reconnoitering female representation in the grade nine textbook of Nepal. Before the study, it was assumed that, in this twenty first century, the textbook must have been written harmonizing gender. However, after analyzing the text carefully and critically from feminist perspective, it has been found that the textbook is found to be biased in terms of gender. It presents females as weak, secondary, dependent upon males, inferior, irrational, powerless and victims and males as independent, superior, rational, powerful and primary. The analysis of data show that male are given higher occupational roles such as doctor, engineer, reporter, and so on. On the other hand, females are given conventional, nurturing and lower prestigious roles. Likewise, in the text, it has been portrayed that most of the conversations have been initiated by male characters, and they are followed by females. It presupposes that female should speak less and should speak only after listening to males.

By this study, it can be inferred that the textbook writers should balance gender equality while designing textbook. If they do not consider gender equality, there is danger of transferring ideas and notions that are favorable for males, and which may develop inferiority feeling and humiliation among female students. Similarly, it is evoked that, if unequal representation is found in the textbook, teacher needs to be aware and careful while selecting and using such teaching learning materials. No matters how females are portrayed in the textbook, teacher should behave and address equally to both male and female students. Similarly, teacher should encourage both males and females students and give equal opportunity to them to participate in all activities such as speech, drama, sports so that the female students do not feel inferior to males.

\section{REFERENCES}

[1] Bhusal, A. (2019). Addressing FYC instructors' lack of technological expertise in implementing multimodal assignments. In Marginalia in Modern Learning Contexts (pp. 166-186). IGI Global.

[2] Bhusal, A. (2017). Emphasizing the suppression of feminist voices. International Journal of Humanities and Cultural Studies, 4(2), 53-57.

[3] Bhusal, A. (2017). The Rhetoric of racism and anti-miscegenation laws in the United States. IAFOR Journal of Arts and Humanities, 4(2). https://doi.org/10.22492/ijah.4.2.07

[4] Cameron, D. (1992). Feminism and linguistic theory (2nd ed.). London: Macmillan.

[5] Cunningsworth, A. (1995). Choosing your course book. Oxford: OUP.

[6] Hooks, B. (2000). Feminism is for everybody: Passionate politics. Cambridge, MA: Southend press.

[7] Hutchinson, T., \& Torres, E. (1994). The textbook as agent of change. English language teaching journal, 48, 315-328.

[8] Joshi, R.B., Joshi, L. \&Dhungana, P. (2016). Grade nine English textbook. Bhaktapur: Curriculum development center.

[9] Kress, G., \& van Leeuwen, T. (1996). Reading images: The grammar of visual design. London: Routledge.

[10] Lazar, M., M (2007). Feminist critical discourse analysis: articulating feminist discourse praxis. Critical discourse studies, 4, 14-164.

[11] Lohani, S. (2019). The history of multimodal composition, its implementation, and challenges. The Criterion: An International Journal in English 10(1), 118-130.

[12] Lohani, S. (2019). Constructing Nontraditional Rhetoric: Critical Study on GloriaAnzaldua and Suresh Canagarajah. Journal of Research Innovation.9(1), 115-123.

[13] Joshi, P., Lohani, S., and Kafle, R. (2015). Scholars' Social Studies and Creative Arts Series for Primary Level Students, approved by Curriculum Development Centre Nepal, Kathmandu: Scholars Publications and Printing Pvt. Ltd.

[14] Mills, S. (2005). Feminist stylistics. London: Taylor \& Francis e- Library.

[15] Scollon, R. (2001). Action and text: Towards an integrated understanding of the place of text in social (inter)action, mediated discourse analysis and the problem of social action. In R. Wodak\& M. Meyer (Eds.), Methods of critical discourse analysis, 139-183. London: Sage.

[16] Sharma, R. (2017). Feminist perspective in the translated autobiographical essay jeevankaandaakiphool. An unpublished M.Ed. Thesis, Tribhuvan University, Kathmandu.

[17] Sheldon, L. E. (1988). Evaluation ELT textbooks and materials. English language teaching journal, 42, 237- 246.

[18] Spender, D. (1985). Man made language (2nd ed.). London: Routledge and Kegan Paul. 
[19] Tyson, L. (2006). Critical theories today: A user-friendly book. London: Rutledge.

[20] Ur, P. (2009). A course in language teaching. Cambridge University press.

\section{AUTHORS' BIOGRAPHY}

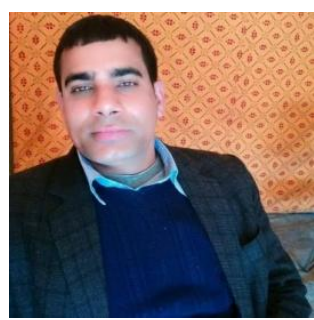

Jagadish Paudel is a faculty member at the Central Department of Education, Tribhuvan University (TU). He is currently pursuing his $\mathrm{PhD}$ in Rhetoric and Composition at the University of Texas at El Paso. He has completed his M.A. and M. Ed. in English from TU, Nepal. He has worked in the field of ELT for twelve years, and has presented his research at national and international conferences. His areas of interest include critical pedagogy, learner autonomy, and rhetoric and writing studies.

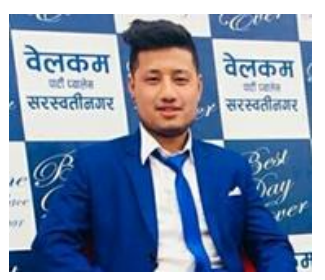

Prabin Khadka has an M.ED. Degree in English Education from TU.

Citation: Jagadish Paudel, Prabin Khadka. "Analysis of an English Textbook from a Feminist Perspective". International Journal of Humanities Social Sciences and Education (IJHSSE), vol. 6, no.9, 2019, pp. 10-21. doi: http://dx.doi.org/10.20431/2349-0381.0609002.

Copyright: () 2019 Authors. This is an open-access article distributed under the terms of the Creative Commons Attribution License, which permits unrestricted use, distribution, and reproduction in any medium, provided the original author and source are credited. 